Research Article

\title{
Influence of Language Anxiety and Prior Knowledge on ESL Students' Achievement in Expository Essay in Ibadan North LGA, Nigeria
}

\author{
Oladotun Opeoluwa Olagbaju \\ School of Arts and Sciences, University of the Gambia, Brikama, Gambia \\ Correspondence should be addressed to Oladotun Opeoluwa Olagbaju; dotunolagbaju@yahoo.com
}

Received 5 March 2021; Revised 3 June 2021; Accepted 9 June 2021; Published 16 June 2021

Academic Editor: Ehsan Namaziandost

Copyright (C) 2021 Oladotun Opeoluwa Olagbaju. This is an open access article distributed under the Creative Commons Attribution License, which permits unrestricted use, distribution, and reproduction in any medium, provided the original work is properly cited.

\begin{abstract}
Recent research efforts in teacher education in Nigeria have largely focused on innovative instructional delivery with little attention to learner-related variables such as language anxiety and prior knowledge that can influence learning outcomes in English composition in ESL classrooms. Notwithstanding these interventions, the problems of mass failure and poor quality of essays still persist in Nigerian schools. Studies have confirmed that language-related anxiety and prior knowledge in ESL classroom can influence students' achievement irrespective of the quality of instruction received by learners in a second/foreign language classroom. Therefore, this study examined the relationship between language anxiety and prior knowledge on achievement in expository essay. Three null hypotheses were tested at a 0.05 level of significance, and 350 participants were randomly selected from four senior secondary schools. Data were collected using two research instruments and the results showed that there was no significant relationship between the independent variables and students' achievement in expository essay. Also, there were no composite and relative contributions of language anxiety and prior knowledge on students' achievement in expository essay. The study was concluded by making recommendations to ESL teachers and students on how to improve achievement in expository writing.
\end{abstract}

\section{Introduction}

The English language is unarguably the status language in Nigeria because it is assigned important roles such as the language of instruction in school, official language, and a core requirement for admission into higher institutions of learning in the country. The importance of English language in the Nigerian educational system is underlined by the fact that the subject is taught and learned at all levels of education and evaluation of students' learning in other subject areas is largely conducted in English. It is also not uncommon to assess one's level of education to the quality of one's writing or speech in English language. Therefore, composition writing is an integral aspect of English instruction in schools, it is also examined in English Language Paper 1 in West African Examination Council (WAEC), and National Examination Council (NECO) conducted examinations in
Nigeria. Paper 1 tests the writing skill in English language, and Olagbaju and Jimoh [1] have argued that any student who wishes to succeed in English must do well in the written aspect of the exam.

Different writing tasks such as letter writing, speech and article writing, and argumentative/debate, narrative, descriptive, and expository essay types are taught and examined in ESL classrooms in Nigeria. However, expository writing is the most demanding because it requires learners to have a grasp of both the linguistic and technical knowledge of the essay. Reference [2] describes expository essay as a form of writing that is intended to inform, enlighten, and educate the readers. Expository writings require students to transmit their ideas, opinions, and facts to the reader and they could be requested to produce an essay that is suitable for publication in a national/local magazine. In spite of the importance of English to students' success in education and 
academic advancement in Nigeria, many students still find the subject difficult to pass especially in the public examinations.

The WAEC Chief Examiners [3, 4] highlight students' poor understanding of the essay questions, errors in grammar, spelling, and punctuation as some of the factors responsible for poor performance in essay writing in particular and English language in general. The report concluded that teachers need to help candidates by teaching them the requirements of the different aspects of the examination, especially essay writing. This is perhaps why most of the efforts aimed at ameliorating the problem of mass failure in English language examinations in Nigeria have largely been focused on teacher and instructional-related variables. Some of the previous studies have investigated the effect of teachers' questioning behaviour and instructional organisation [5], teachers' communication styles [6], and so on.

Although these studies reported the effectiveness of teacher-related factors in improving students' achievement in different aspects or skills of the English language, performance in the subject in public examinations has not improved significantly. This is because there are several other learnerrelated factors such as cognitive style, gender, language exposure, verbal ability, vocabulary knowledge, language anxiety, and prior knowledge that are able to influence or contribute to students' learning outcomes in ESL classroom. Success in English language examination at WAEC- and NECO-conducted examinations has been strongly tied to students' ability to succeed in the written aspect of the examination. Expository essay is a regular question type in the essay or composition section of the examination every year. Writing an expository essay presents at least two challenges to the second language learner: he or she must demonstrate a mastery of the rudiments of the target language and the knowhow on the technicalities of the topic to be written on.

Demonstrating a mastery of the writing skills or use of the target language can be very challenging for a second language learner. It is often in form of a mild or pronounced apprehension or anxiety in a second language classroom. In actual fact, several language teachers have acknowledged the existence of language-induced anxiety in second/foreign language classrooms and its influence on students' performance in the target language [7-9]. Similarly, learnercentred variables such as language anxiety and prior knowledge are prevalent in most Nigerian classrooms. This is because most learners have acquired the mastery of their mother tongue before the fourth year of primary/basic education when English "progressively" becomes the language of instruction in the classroom [10].

According to [11], the implication of the Nigerian educational policy is that learners have to learn English (as a second language) and learn with English at the same time. Most of the learners struggle to learn English and with the English language, especially because they unassumingly transfer the rules, styles, and pronunciation of the first language $\left(\mathrm{L}_{1}\right)$ to the second language $\left(\mathrm{L}_{2}\right)$ classroom. Learners' prior knowledge in $\mathrm{L}_{1}$ is capable of creating anxiety that hinders the learning or acquisition of $\mathrm{L}_{2}$ in most ESL classrooms.
In line with the aforementioned points, [12] posits that second/foreign language learning experience can be demanding because of the feeling of anxiety that most ESL/EFL learners experience. Often, the second or foreign language learners encounter anxiety as a feeling of apprehension, nervousness, and pressure associated with the learning of a new language in a second or foreign language atmosphere. Reference [7] describes anxiety as one of the dominant psychological factors in most second language classrooms. This suggests that language anxiety can hinder or support second language acquisition or learning processes. In [13], language anxiety is a product of transfer of apprehension to language learning situations or a response to unfamiliar stimuli in the process of learning a language. Such anxieties, if unfettered, are capable of hindering the language learning process or making the experience unpleasant. Therefore, language anxiety is an implicit or explicit kind of apprehension exhibited by language learners in a foreign/second language classroom.

It is not all forms of anxiety that are bad because some anxieties can be helpful in motivating or facilitating the desired change while the harmful or negative anxiety hinders learning performance [14]. It is also possible for second language learners' anxiety to be neutral and it has no impact on the language learning process. In view of the inconclusive nature of anxiety and its role in language learning situations, this study determines the influence of language anxiety on ESL students' achievement in expository essay.

One of the factors responsible for anxiety during a second/foreign language instruction is how well learners are able or not able to integrate the new instruction into their schema. That is a situation where learners do not have prior knowledge that aids in recall or transfer of learning, which serves as a platform for the new knowledge. Prior knowledge refers to the sum of relevant body of knowledge or experience possessed by learners relevant to the task they are expected to perform. Reference [15] avers that prior knowledge helps students to recall and make use of what they have been taught through a complex network of interrelated information that they bring to the classroom. Prior knowledge and experiences influence the thinking of ESL learners in the language classroom and new learning experiences are often constructed based on their prior knowledge.

Similarly, prior knowledge deals with the meta-cognitive aspect of learning especially when learners need to compose or brainstorm before or during the process of writing an expository essay. There is no vacuum in the construction of knowledge because the new body of knowledge has to be built on some old understanding or prior knowledge. This is perhaps why [16] submits that the higher the volume of prior knowledge an individual possesses is, the lesser the instructional support that is needed, and the lesser the prior knowledge an individual possesses is, the higher the support will be needed. The concern of this study is that the interaction between students' prior knowledge and anxiety in ESL classroom is capable of determining students' level of success irrespective of the teacher-related factors such as subject mastery, qualification, choice of instructional 
strategy, and the quality of corrective feedback in the classroom. Therefore, the concern of this study is to examine the relationship between language anxiety and prior knowledge on ESL students' achievement in expository essay.

1.1. Statement of the Problem. The National Policy on Education (NPE) in Nigeria recommends the progressive use of English as the language of instruction for ESL learners from the fourth year of the primary/basic school after most of the learners had already acquired the mastery of the basic communication skills in their mother tongue. By implication, most ESL learners in Nigeria are confronted with the realities of language anxiety and prior knowledge in the learning of the target language, and this is largely responsible for the perennial mass failure in English language in public and private examinations. Efforts to improve students' performance in English language and essay writing in particular have largely focused on pedagogical innovations with little attention to learner-related variables such as language anxiety and prior knowledge that can influence learning outcomes in ESL classrooms. In spite of these interventions, the problems of mass failure and poor quality of essays still persist. Studies have confirmed that languagerelated anxiety and prior knowledge in ESL classroom can influence students' performance irrespective of the quality of instruction in a second/foreign language classroom. Most of the previous studies on learner-related factors in second language learning considered variables such as cognitive style, gender, maturation, foreign language anxiety, and vocabulary knowledge, with little emphasis on the relationship between language anxiety and prior knowledge on students' achievement in essay writing in ESL classroom. Therefore, this study determined the relationship between language anxiety and prior knowledge on achievement in expository essay in Ibadan North LGA, Nigeria.

1.2. Hypotheses. Based on the stated problems, the following null hypotheses were tested at a 0.05 level of significance.

Hol: there is no significant relative relationship between the independent variables (language anxiety and prior knowledge) and students' achievement in expository essay

Ho2: there is no significant composite contribution of independent variables (language anxiety and prior knowledge) and students' achievement in expository essay

Ho3: there is no significant relative contribution of independent variables (language anxiety and prior knowledge) and students' achievement in exposition essay

1.3. Theoretical Framework: Anderson's Schema Theory. The theory was developed mostly in the 1970s by American educational psychologist, Richard Anderson. Schema theory describes how knowledge is acquired, processed, and organised. Schema or schemata refer to a mental framework used by humans used to represent and organise information, which aids in easy recall. These schemata are building blocks of cognition derived from learners' experiences or prior knowledge and they enable us to recall, modify our behaviour, concentrate our attention on key information, or try to predict the most likely outcomes of events. Schema influences the processes involved in students' interest and ability to pay attention and absorb new knowledge: people are more likely to notice things that fit into their schema. The theory further states that people can quickly organise new perceptions into schemata and act without effort. Schema theorists suggest that knowledge is organised through an elaborate mental activity, which involves prior knowledge, cognitive processing, and memory recall. Similarly, this study involves how psycholinguistic and cognitive factors such as language anxiety and prior knowledge contribute to students' active participation in the learning process through cognitive processing and memory recall in the process of second language instruction with the aid of the learners' schema. These factors enable the learners to actively participate and facilitate learning during the process of classroom instruction. ESL students often construct their learning by relying on their schema to actively generate their own learning. The theory is applicable to this study in the sense that schema-related factors such as language anxiety and prior knowledge play every important role in ESL instruction and they can be maximised to improve learning experience and learning outcomes.

\subsection{Language Anxiety and Prior Knowledge as Factors in ESL} Students' Learning Outcomes. English language instruction in Nigeria is largely used as a second language in schools because most of the learners live in indigenous linguistic environment and must have acquired at least one indigenous language as a mother tongue before the official school age. This is why the NPE [10] states that the use of English as the medium of instruction in Nigerian schools should commence progressively from basic (primary or grade) four. When language learners have acquired the requisite skills of a language before learning a new language, several learnerrelated factors, which include language anxiety and prior knowledge, are likely to interfere with learning outcomes and the process of instruction in ESL classrooms.

Learners' anxiety is a common phenomenon during instructional procedural processes, especially if the topic, method, or teaching style is unfamiliar. Prevalence of language anxiety in a second language classroom is capable of affecting the teaching and learning of the four language skills, particularly the writing skill. Language anxiety in the classroom is the worry or apprehension encountered by the second or foreign language learners, which is capable of hindering effective learning of the target language. Teachers play an important role in enriching students' learning experiences and they could trigger anxiety in the second language classroom without taking note of it. As a factor in second language learning situations, it is important that language anxiety should be detected early and assistance or 
support should be provided for language learners in and out of the classroom.

Reference [12] avers that learning a second/foreign language in a multilingual setting is an onerous task because of the apprehension displayed by most ESL/EFL learners in the process of language learning, which often makes the experience less enjoyable. The reality of overt or covert anxieties based on the learning and acquisition of the target language in ESL classrooms suggests that teachers should pay close attention to such factors. For example, [9] submits that several language teachers have acknowledged the existence of language anxiety in ESL/EFL classrooms and its influence on students' performance in the target language. According to [17] and Dewey, Belnap, and Steffen (2018), language anxiety was found to hinder language learning especially in the development of the four skills and they recommended that efforts should be made to find out areas of ESL students' concerns, calm such down, and investigate the sources of their apprehensions. This can be because the process of learning is both cognitive and affective; therefore, when ESL learners approach instruction in the target language with anxiety or apprehension, effective learning cannot take place. The social aspect of language anxiety can affect ESL learners' confidence level and self-esteem when it comes to effective communication in the target language.

Reference [18] describes language anxiety as a communication-related apprehension arising from ESL/EFL learners' inability to adequately express themselves, fear of negative social evaluation arising from a need to make a positive impression on others, and test anxiety arising from worry about academic achievement. For [19], there is a distinction between test apprehension and language anxiety because language anxiety is a product of nervousness in communication or fear of social evaluation while test anxiety is a general problem, which is not dependent on language anxiety. Language anxiety is a subjective variable in ESL/EFL situations and [20] describes it as an important factor in individual differences in second language acquisition which teachers need to pay attention to. References $[12,17]$ found the influence of language anxiety on ESL/EFL students' learning outcomes to be significant and suggested that teachers need to reduce the negative effects of anxiety in ESL classrooms.

Apart from language anxiety, prior knowledge also plays a prominent role in second language learning. Prior knowledge covers the total of the relevant skills, aptitude, and know-how that a learner possesses before coming into contact with a new body of knowledge or information. Prior knowledge aids in recall or transfer of knowledge and they can be in form of either misconceptions or alternative conceptions [21]. Prior knowledge deals with the students' schema and the cognitive aspect of learning. In second language situations, for example, ESL students' prior knowledge does not exist as separate or independent threads of information but as an intricate network of interrelated previous knowledge. Therefore, students' prior knowledge can be used to enhance the quality of instruction and improve students' learning outcomes in ESL classrooms. Reference [16] submits that there is a connection between prior knowledge and instruction because learners with a high volume of prior knowledge require less instructional support. However, [16] statement can only be said to be true if the students' prior knowledge is supportive of the new body of knowledge. But if the prior knowledge or schema cannot accommodate the new content or instruction in the target language, ESL students would either struggle or transfer unwholesome content from the prior knowledge in their first language to the target language.

Prior knowledge can be subjective in a teaching and learning process and it is one of the factors that account for individual differences in classrooms. Prior knowledge exists in all ESL classrooms and it is capable of influencing the course of instruction and students' learning outcomes in the target language. Teachers should be conscious of students' prior knowledge so as to plan their instructions to appeal to their students' schema. Reference [22] investigated the role of prior knowledge in the development of strategy flexibility in computational estimation and found that prior knowledge impacted the development of flexibility. Similarly, Thompson and Zamboanga examined the role of prior knowledge on flexibility in the use and knowledge of strategies in mathematics. The result showed that prior knowledge, self-belief, and previous study success were positively intercorrelated with prior knowledge and previous study success showing the strongest positive correlation with the final grade. However, studies on the influence of language anxiety and prior knowledge on students learning outcomes have largely focused on mathematics, computer programming, and other science-related subjects with little or nothing on essay writing. Therefore, this study examines the influence of language anxiety and prior knowledge on students' learning outcomes in expository essay in Ibadan North LGA of Oyo State, Nigeria.

\section{Research Methodology}

2.1. Research Design, Population, and Sampling Procedure. The study adopted a descriptive research design of survey type. The population consists of all the senior secondary school students in Ibadan North LGA of Oyo State, Nigeria. Simple random sampling was used to select four schools from the public schools in the LGA and a total of 350 SS2 students were randomly selected for the purpose of this study.

2.2. Variables. The independent variables are language anxiety and prior knowledge while the dependent variable is ESL students' achievement in expository essay.

2.3. Instruments and Validation Process. Two instruments were used in this study. The first instrument, Language Anxiety and Prior Knowledge Questionnaire (LAPKQ), was designed by the researcher. LAPKQ is a 28 -item questionnaire that has three parts: the first part requested demographic information from the participants, the second aspect on language anxiety comprises 15 items with a three-point scoring scale of Always (3), Rarely (2), and Never (1), the 
third aspect is on prior knowledge and it consists of 13 items with a two-point scale of Yes (2) and No (1). LAPKQ was subjected to face validation through review by lecturers in educational psychology and language education. For content validity, there was a pilot test using a sample of 35 students with similar characteristics but not part of population for the study. Cronbach alpha statistics was used to analyze their responses and a coefficient of 0.78 was recorded. The second instrument is Achievement Test in Expository Writing (ATEW). The instrument is a standardised test because it is a past WAEC question on expository essay, written under similar examination conditions and was marked by WAEC examiners using WAEC-recommended raters' guide.

2.4. Procedure for Data Collection and Analysis. The process of data collection lasted for a period of three weeks. LAPKQ and ATEW were administered simultaneously and the data collected from participants were processed for analyses. The AREW was marked by seasoned WAEC examiners with at least five years of marking experience and the questionnaire was scored for analysis. The data were analyzed using inferential statistics such as Pearson Product Moment Correlation (PPMC), mean and standard deviation.

\subsection{Findings of the Study}

Hol: there is no significant relative relationship between the independent variables (language anxiety and prior knowledge) and students' achievement in expository essay.

Table 1 shows the relationship each of the independent variables (language anxiety and prior knowledge) had with students' achievement in expository essay. The result indicates that language anxiety had a negative insignificant relationship with students' achievement in expository essay $(r=-0.029 ; p>0.05)$. This implies that language anxiety influenced students' achievement in expository essay. The table also indicates that prior language had a negative insignificant relationship with students' achievement in expository essay $(r=-0.052$; $p>0.05)$. This also implies that students' prior language has a negative influence on their achievement in expository essay. Based on these results, the null hypothesis one that there is no significant relative relationship between the independent variables (language anxiety and prior knowledge) and students' achievement in expository essay is hereby not rejected.

Ho2: there is no significant composite contribution of independent variables (language anxiety and prior knowledge) and students' achievement in expository essay.

The result showed that there was no significant composite contribution of language anxiety and prior knowledge to students' achievement in expository essay $\left(F_{(2 ; 347)}=.504 ;\right.$ Adj. $\left.R^{2}=-0.003 ; p=0.605>0.05\right)$. This implies that the two independent variables when pulled together did not significantly contribute to students' achievement in expository essay. Therefore, the null hypothesis 2 is hereby not rejected.

Ho3: there is no significant relative contribution of independent variables (language anxiety and prior knowledge) and students' achievement in exposition essay.

The result showed the relative contribution of each of the independent variables (language anxiety and prior knowledge) to students' achievement in exposition essay. The result indicates that there is no significant relative contribution of language anxiety $(\beta=-0.014 ; p=0.809>0.05)$ and prior knowledge $(\beta=-0.048 ; p=0.396>0.05)$ to students' achievement in exposition essay. This implies that the language anxiety and prior knowledge did not individually contribute to students' achievement in expository essay. Therefore, the null hypothesis 3 is hereby not rejected.

\section{Discussion of the Findings}

From the foregoing, the findings of this study showed that language anxiety and prior knowledge had a negative insignificant relationship with students' achievement in expository essay. This result implies that a high level of language anxiety in the ESL classroom led to poor achievement in expository essay. The findings of this study support similar studies such as $[7,13,17]$ that found that language anxiety, if not remedied by the teacher, is capable of hindering the language learning process or making the experience unpleasant in a foreign language classroom. However, the findings of this study are for second language learners in Nigeria who have been found to often exhibit implicit or explicit kind of anxiety within and outside the classroom because of the strong influence of prior knowledge in their mother tongue or $\mathrm{L}_{1}$. However, the findings of this study on language anxiety are at variance with [14] that found that students' anxiety concerning learning a concept or subject can be helpful in motivating or facilitating them to learn such concept. Also, [8] avers that anxiety can be an impetus for learning a language. The findings of this study have shown that ESL teachers need to be conscious of learning anxiety in the classroom and assist them to overcome such apprehensions in the language teaching and learning process.

The study also found that prior knowledge had no significant relationship with students' achievement in expository essay. This result disagrees with $[21]$ and $[22,23]$ that found the relationship between prior knowledge and students' achievement to be positively significant in subject areas such as mathematics and computer science. The result of this current study however can be because the study is languagerelated and the universal nature of language aided the students to draw possible links between their mother tongues and the target language. Another possible explanation for this result is that the study examined the influence of prior knowledge on students' achievement in essay writing where concepts such as brainstorming and sentence construction can be easily generated in the first language and transferred to the target language with little or no mistake. Perhaps, other 
TABLe 1: Relative relationship of independent variables with students' achievement in expository essay.

\begin{tabular}{lccc}
\hline Variables & Students' achievement in expository essay & Language anxiety & Prior language \\
\hline Students' achievement in expository essay & 1 & 1 & \\
Language anxiety & $-0.029(0.593)$ & $0.3122^{*}(0.000)$ & 350 \\
Prior knowledge & $-0.052(0.330)$ & 25.18 & 350 \\
$N$ & 350 & 17.04 & 6.65 \\
Mean & 6.77 & 3.01 \\
Standard deviation & & \\
\hline
\end{tabular}

skills of English language such as speaking and reading could have produced a different result because students would not have been able to produce or account for sounds that are not available in their mother tongue or first language.

The findings of this study on language anxiety suggest that ESL teachers must ensure that students' apprehensions are addressed through the use of quality instruction, which are interactive and communicative so that corrective prompt feedback can be provided to support students' learning of the target language (see [6]). In addition, the findings of this study showed that there is no significant composite contribution of language anxiety and prior knowledge to students' achievement in expository essay. To the best knowledge of the researchers, the composite contribution of the two independent variables in expository essay as examined in this study has not been investigated in any other study. However, the findings of this study are at variance with the results of several other studies that found that language anxiety and prior knowledge contribute significantly to students' learning outcomes.

Lastly, the findings of this study showed that there is no significant relative contribution of learning anxiety and prior knowledge to students' achievement in expository essay. The result disagrees with the other previous studies $[9,12,15,16]$ that showed that factors such as language anxiety and prior knowledge have significant relative contributions to students' achievement across different subject areas. The implication of this study is that each of language anxiety and prior knowledge, when examined separately, does not contribute to students' achievement in expository essay. This result supports [20] that revealed that other forms of apprehension within the classroom, aside from language anxiety, are capable of contributing to students' achievement in a language classroom. Although learning a second language in a multilingual setting like Nigeria can be demanding, factors such as strong interference of students' mother tongue, lack of recommended textbooks, poor quality of instruction, emotional instability, and test apprehension can create unnecessary anxiety for learners within the ESL classroom and lead to poor achievement that may not be directly connected to language anxiety. For example, [19] found that there are several causes of anxiety within the second language classroom apart from language anxiety and these factors can influence students' performance in the target language.

\section{Conclusion and Recommendations}

In most Nigerian classrooms, instruction in English language begins after learners have acquired the basic skills in their mother tongue or first language. However, the English language is the language of instruction from the fourth year of primary education, a core subject and major requirement for progress to the other levels of education in the country. Success in the subject, especially in public examination, has been found to be largely determined by learner-related factors such as language anxiety and prior knowledge. Studies have reported that the perennial mass failure in English language is because students do not do well in the aspect of the examination on essay writing. Therefore, essay writing in general and expository essay in particular are an integral aspect of instruction in English composition in ESL classrooms within Ibadan North LGA. However, students have been found to avoid writing this type of essay and when they do, students' achievement in expository essay has been very poor. This is because this essay type requires learners to demonstrate the knowledge of selected concepts which may include the incorporation of relevant facts and figures. Hence, students' schema or prior knowledge and language anxiety are capable of enhancing or impeding achievement in this type of English composition. Therefore, the study examined the relationship between language anxiety and prior knowledge and students' achievement in expository essay in ESL classrooms. The findings of this study showed that there are no significant relationships between language anxiety and prior knowledge and achievement in expository essay. Also, there are no composite and relative contributions of the independent variables on students' achievement in expository essay in Ibadan North Local Government Area of Oyo State, Nigeria.

Based on this result, the following recommendations are made:

(1) ESL teachers need to consider language anxiety more closely in the classroom and remedy such apprehensions through quality instructional delivery.

(2) Teaching English in ESL classroom should be highly interactive and communication-based, and corrective feedback must be detailed and prompt.

(3) The primary responsibility of language teachers should be to create a connection between students' schema and the new body of knowledge.

(4) ESL teachers should begin to focus more on prevailing learner-related variables within the classroom such as language anxiety, prior knowledge, verbal ability, and vocabulary knowledge that can influence students' achievement irrespective of the quality of the instruction that they received in the classroom. 


\section{Data Availability}

The data used to support this study are included in the manuscript.

\section{Conflicts of Interest}

The author declares that there are no conflicts of interest.

\section{References}

[1] O. O. Olagbaju and N. O. Jimoh, "Language exposure and subject familiarity as correlates of senior secondary school students' achievement in narrative writing," Technium Social Sciences Journal, vol. 7, no. 1, pp. 98-106, 2020.

[2] T. Akinborewa and O. O. Olagbaju, Simplified Composition Workbook, Joytal Printing Press, Ibadan, Nigeria, 2010.

[3] West African Examination Council, "English language: WAEC highlights candidates' weaknesses in WASSCE exams," Daily Independent, 2020.

[4] West African Examinations Council, Chief Examiners' Report for the West African Senior School Certificate Examination (WASSCE), WAEC Press, Lagos, Nigeria, 2019.

[5] D. O. Fakeye and E. Ayede, "Teachers' questioning behaviour and instructional organisation as correlates of students' achievement in english language," Global Journal of Human Social Sciences Linguistics \& Education, vol. 13, no. 2, pp. 13-22, 2013.

[6] K. O. Ogunyemi and O. O. Olagbaju, "Effects of assertive and aggressive communication styles on students' self-esteem and achievement in english language," Cross-Cultural Communication, vol. 16, no. 1, pp. 96-101, 2020.

[7] D. P. Dewey, R. K. Belnap, and P. Steffen, “Anxiety: stress, foreign language classroom anxiety, and enjoyment during study abroad in Amman, Jordan," Annual Review of Applied Linguistics, Cambridge University Press, vol. 38, pp. 140-161, , Cambridge, UK, 2018.

[8] E. Horwitz, "Language anxiety and achievement," Annual Review of Applied Linguistics, Cambridge University Press, vol. 21, pp. 112-126, , Cambridge, UK, 2001.

[9] K. William and M. Andrade, "Foreign language learning anxiety in Japanese EFL university classes: causes, coping and locus of control," Electronic Journal of Foreign Language Teaching, vol. 5, no. 2, pp. 181-191, 2008.

[10] Federal Republic of Nigeria, National Policy on Education (Revised), NERDC Press, Abuja, Nigeria, 2013.

[11] O. O. Olagbaju, The Challenges of Using Nigerian Languages in Modern Education, University of Ibadan, Ibadan, Nigeria, 2009.

[12] M. J. Riasati, "Language learning anxiety from EFL learners' perspective," Middle-East Journal of Scientific Research, vol. 7, no. 6, pp. 907-914, 2011.

[13] S. Donkaewbua, "Developing an anxiety in vocabulary learning through listening scale," International Journal of Language and Linguistics, vol. 3, no. 6, pp. 60-71, 2016.

[14] G. Spielmann and M. L. Radnofsky, "Learning language under tension: new directions from a qualitative study," The Modern Language Journal, vol. 85, no. 2, pp. 259-278, 2001.

[15] L. Wenk, The Importance of Engaging Prior Knowledge, Hampshire College Center for Teaching and Training, Amherst, MA, USA, 2017.

[16] D. H. Jonassen and B. L. Grabowski, Handbook of Individual Differences, Learning and Instruction, Lawrence Erlbaum Associates, Inc, Mahwah, NJ, USA, 1993.
[17] E. Şenel, "Foreign language anxiety of students studying english language and literature: a sample from Turkey," Educational Research and Reviews, vol. 11, no. 6, pp. 219-228, 2016.

[18] E. K. Horwitz, M. B. Horwitz, and J. Cope, "Foreign language classroom anxiety," The Modern Language Journal, vol. 70, no. 2, pp. 125-132, 1986.

[19] P. D. MacIntyre and R. C. Gardner, "language anxiety: its relationship to other anxieties and to processing in native and second languages," Language Learning, vol. 41, no. 4, pp. 513-534, 1991.

[20] L. Honggand, "New insights into language anxiety: theory, research and educational implications," ELT Journal, vol. 73, no. 1, pp. 105-107, 2019.

[21] P. A. Alexander, "Domain knowledge: evolving themes and emerging concerns," Educational Psychologist, vol. 27, no. 1, pp. 33-51, 1992.

[22] R. Star, B. Rittle-Johnson, K. Lynch, and N. Perova, "The role of prior knowledge in the development of strategy flexibility: the case of computational estimation," ZDM-International Journal of Mathematics Education, vol. 41, no. 5, pp. 569-579, 2009.

[23] R. A. Thompson and B. L. Zamboanga, "Prior knowledge and its relevance to student achievement in introduction to psychology," Teaching of Psychology, vol. 30, no. 2, pp. 96-101, 2003. 